\title{
Analisis Partial Discharge Pada Saluran Kabel Tegangan Menengah 20 kV (Studi Assesmen SKTM di PT. PLN (Persero) UP3 Menteng) \\ ${ }^{1}$ Irfan Nurhadi , ${ }^{2}$ Parjiman , ${ }^{3}$ Mochammad Djaohar \\ 1,2,3 Pendidikan Teknik Elektro, Fakultas Teknik, Universitas Negeri Jakarta \\ 1,2,3Email: irfan.nurhadi69@gmail.com ; parjiman@unj.ac.id ; djaohar@unj.ac.id
}

\begin{abstract}
This study aims to determine the status of the cable condition to the emergence voltage of Partial Discharge, as well as the status of the cable to discharge the Partial Discharge. Measurements were made at PT PLN (Persero) UP3 Menteng on TD 09-PM 4A Segment Goat Feeders. This research uses a descriptive method. This study carried out measurements of the release of charge and voltage at each phase in the segment. After measuring the discharge of a single segment, data analysis is then performed to determine the value of Partial Discharge, then the value is accumulated to conclude the condition of cable failure risk that refers to standards set by PLN.The results showed that the status of the cable to the voltage appears Partial Discharge. PDIV value of $17.3 \mathrm{kV}$ can be interpreted PDIV > Uo. PDEV value of $8 \mathrm{kV}$, can be interpreted PDEV $\left\langle U_{0}\right.$. So that PDIV > $U_{0}$ and PDEV $<U_{0}$ fall into the category of cable status quite poorly with Point 2. Cable Status Against Load Discharge. PD max and PD Level values range below $500 \mathrm{pC}$. So that the load can be interpreted as below or equal to $500 \mathrm{pC}, Y<500 \mathrm{pC}$ or $Y=500 \mathrm{pC}$ in the cable status category either with point 1 . If pont 2 and point 1 are added up then the result is point 3. Point 3 can be concluded with dark green. The risk of cable failure in the TD 09 to PM 4A segment is low and the cable status is quite good. The follow up is that within a period of 12 months, this segment must be re-measured to determine the condition of the risk of cable failure.
\end{abstract}

Keywords: SKTM, Partial Discharge, PDIV, PDEV, Risk of Cable

\begin{abstract}
Abstrak
Penelitian ini bertujuan untuk untuk mengetahui status kondisi kabel terhadap tegangan munculnya Partial Discharge, serta status kabel terhadap pelepasan muatan Partial Discharge. Pengukuran dilakukan di PT PLN (Persero) UP3 Menteng pada Penyulang Kambing Segmen TD 09-PM 4A. Penelitian ini menggunakan metode deskriptif. Penelitian ini dilakukan pengukuran pelepasan muatan dan tegangan pada setiap fasa pada segmen tersebut. Setelah dilakukan pengukuran pelepasan muatan satu segmen maka selanjutnya dilakukan analisis data untuk mengetahui nilai Partial Discharge kemudian nilai tersebut diakumulasikan hingga menjadi kesimpulan kondisi resiko kegagalan kabel yang mengacu pada standar yang telah ditentukan oleh PLN. Hasil penelitian menunjukkan bahwa status kabel terhadap tegangan muncul Partial Discharge. Nilai PDIV sebesar 17,3 kV perfasa dapat diartikan PDIV > Uo. Nilai PDEV sebesar $8 \mathrm{kV}$ perfasa, dapat diartikan PDEV $<\mathrm{U}_{0}$. Sehingga PDIV $>\mathrm{U}_{0}$ dan PDEV < $\mathrm{U}_{0}$ masuk kategori status kabel cukup buruk dengan Point 2. Status Kabel Terhadap Besar Pelepasan Muatan. Nilai PD max dan PD Level berkisar dibawah 500 pC. Sehingga dapat diartikan besar muatan dibawah atau sama dengan $500 \mathrm{pC}, \mathrm{Y}<500 \mathrm{pC}$ atau $\mathrm{Y}=500 \mathrm{pC}$ masuk kategori status kabel baik dengan point 1. Jika pont 2 dan point 1 dijumlahkan maka hasilnya poin 3. Poin 3 dapat disimpulkan dengan warna hijau tua. Resiko kegagalan kabel pada segmen TD 09 to PM 4A adalah rendah dan status kabel tersebut cukup baik. Tindak lanjutnya yaitu dalam jangka waktu 12 bulan, segmen ini harus kembali diukur untuk mengetahui kondisi resiko kegagalan kabel.
\end{abstract}

Kata Kunci: SKTM, Peluahan Parsial, PDIV, PDEV, Resiko Kegagalan Kabel

\section{PENDAHULUAN}

Pada sistem tenaga listrik, PT. PLN (Persero) Distribusi Jakarta Raya (Disjaya) yang merupakan perusahaan negara yang menyalurkan energi listrik mulai dari pembangkitan, transmisi, dan juga distribusi ke konsumen. Pendistribusian energi listrik dalam hal ini PT. PLN (Persero) menjaga agar penyaluran energi listrik dapat berjalan dengan baik secara terus menerus tanpa adanya gangguan. Penyaluran sistem distribusi energi listrik terbagi menjadi dua, yaitu dengan
Saluran Udara Tegangan Menengah (SUTM) dan Saluran Kabel Tegangan Menengah (SKTM). Kabel bawah tanah yang biasa digunakan yaitu cross-linked polyethyelene atau yang lebih dikenal dengan kabel XLPE. Dalam jaringan distribusi sering terjadi gangguan yang menyebabkan pendistribusian tenaga listrik ke konsumen menjadi terganggu. Gangguan yang terjadi pada jaringan distribusi diantaranya adalah gangguan SKTM. Gangguan yang terjadi pada SKTM adalah gangguan internal dan gangguan eksternal. Gangguan internal rata-rata disebabkan kecacatan di dalam kabel 
atau sambungan kabel (jointing) menyebabkan Partial Discharge di dalam kabel. Gangguan di wilayah PLN Distribusi Jakarta Raya sering terjadi, gangguan tersebut disebabkan gangguan SKTM. Berdasarkan data gangguan dari PLN UP3 Menteng, jumlah gangguan Saluran Kabel Tegangan Menengah (SKTM) pada tahun 2014 sebanyak 269 gangguan, pada tahun 2015 sebanyak 184 gangguan, pada tahun 2016 sebanyak 157 gangguan, pada tahun 2017 sebanyak 154 gangguan, pada tahun 2018 sebanyak 137 gangguan. Dari data tersebut dapat disimpulkan bahwa gangguan tersebut terjadi dalam jumlah yang cukup banyak

Munculnya Partial Discharge di dalam SKTM dapat menyebabkan kegagalan isolasi. Partial Discharge atau peluahan sebagian ini merupakan bentuk pelepasan muatan listrik yang terjadi hanya pada sebagian dari sistem isolasi yang dapat mengawali kegagalan isolasi peluahan sebagian pada suatu bagian isolasi yang terjadi diakibatkan karena adanya beda potensial yang tinggi. Mendiagnosa Partial Discharge dengan menggunakan metode asesmen kabel yang ada di PLN UP3 Menteng. Partial Discharge Diagnostic dipilih karena untuk melakukan pemeliharaan prediktif maka diperlukan diagnostik yang tidak merusak. Asesmen kabel adalah metode pengukuran kondisi SKTM yang meliputi kegiatan mengukur panjang kabel, Partial Discharge, monitoring whitstand test, cable tracer, dan menganalisis hasilnya serta memberikan rekomendasi untuk bahan tindakan yang akan diperlukan pada segmen kabel yang di asessmen. Untuk menghindari kegagalan pada sistem kabel perlu pengecekan secara berkala dengan menggunakan metode tersebut. Pengujian ini dilakukan untuk memprediksi harapan hidup yang tersisa dari kabel tersebut.

Atas dasar pertimbangan dari masalah gangguan SKTM tersebut, maka peneliti melakukan studi Partial Discharge di penyulang Kambing pada segmen TD 09 PM 4A. Studi Partial Discharge dilakukan dengan metode asesmen kabel. Studi Partial Discharge dilakukan dengan menggunakan alat OWTS (Oscilating Wave Test System) untuk mendeteksi Partial Discharge pada SKTM. Alat tersebut memberikan tegangan DAC (Damp Alternate Current) pada sistem kabel. Sehingga tidak merusak kabel. Hasil dari nilai
Partial Discharge yang telah diketahui dijadikan acuan untuk pemeliharaan SKTM yang akan dilakukan di masa mendatang. Penelitian ini membahas metoda diagnostik kabel $20 \mathrm{kV}$ serta dengan metoda analisan assesmen menggunakan diagnostik Partial Discharge yang dapat dilakukan di lapangan.

\section{METODOLOGI PENELITIAN}

Penelitian ini merupakan studi kasus pada jaringan tegangan menengah. Teknik pengumpulan data dalam penelitian ini dilakukan dengan wawancara dan dokumentasi untuk mendapatkan data sekunder, serta dengan pengujian dilapangan. Wawancara adalah teknik pengumpulan data dengan cara menanyakan sesuatu kepada seseorang yang menjadi informan dengan bercakap-cakap secara tatap muka (Afifuddin \& Saebani, 2012:131). Dalam penelitian ini, wawancara dilakukan bersama pengawas dilapangan dan pegawai PLN yaitu supervisor selaku penanggung jawab, dan pegawai dilapangan yang lebih memahami dan berpengalaman dalam melakukan praktik pengujian.

Dokumentasi yang dimaksud berupa pengumpulan data-data secara tertulis dan objektif yang dimiliki PLN yang berisi laporan gangguan saluran kabel tegangan menengah dengan frekuensi gangguan selama beberapa bulan terakhir, dan beberapa tahun ke belakang. Pengujian serta pengukuran dengan terjun langsung dilapangan atau tempat kejadian mengikuti, mengukur, dan mengamati langsung proses pengujian dilapangan. Dengan panduan pembimbing yang ditunjuk. Dan kepada para ahli yang bertugas di tim asesmen.yang berada dalam lingkup UP3 Menteng yaitu jaringan tegangan menengah pada penyulang Kambing pada segmen TD 09 - PM 4A.

Di pilihnya Penyulang Kambing karena pada satu tahun sebelumnya telah dilakukan pengukuran yang hasilnya status resiko kabel cukup buruk, sehingga perlu diadakan pengukuran terbaru untuk mengetahui kondisi resiko kabel yang terupdate. Adapun metode penelitian yang digunakan adalah metode deskriptif dengan pengukuran disuatu segmen yang sudah ditentukan kemudian menganalisis Partial Discharge yang terjadi pada segmen tersebut. 
Penelitian ini menggunakan metode penelitian Kuantitatif deskriptif. Tujuan dari penelitian deskriptif ini adalah untuk membuat deskripsi, gambaran, atau lukisan secara sistematis, faktual dan akurat mengenai faktafakta, sifat-sifat serta hubungan antar fenomena yang diselidiki.

Penelitian ini dengan mengangkat studi kasus. Metode penelitian studi kasus meneliti suatu kasus atau fenomena tertentu yang ada dalam masyarakat yang dilakukan secara mendalam untuk mempelajari latar belakang, keadaan, dan interaksi yang terjadi. Studi kasus dilakukan pada suatu kesatuan sistem yang bisa berupa suatu program, kegiatan, peristiwa, yang ada pada keadaan atau kondisi tertentu. Karena khusus meneliti suatu hal atau sistem tertentu, penelitian studi kasus bukanlah dilakukan untuk menarik kesimpulan terhadap fenomena dari suatu populasi atau kumpulan tertentu melainkan khusus untuk kejadian atau fenomena yang diteliti saja.

Besar nilai muatan atau partikel yang lepas dari kabel tersebut dianalisis untuk diketahui status kondisi kabel tersebut. Diakhir penelitian, dari nilai partikel atau muatan yang lepas tersebut akan diketahui status resiko kabel tersebut. Apakah terjadi kegagalan isolasi yang masih layak digunakan atau perlu dilakukannya penggantian kabel.

Metode penyelidikan deskriptif tertuju pada pemecahan masalah yang ada pada masa sekarang. Metode ini menuturkan, menganalisa, dan mengklasifikasi; menyelidiki dengan teknik survey, interview, angket, observasi, atau dengan teknik test; studi kasus, studi komperatif, studi waktu dan gerak, analisa kuantitatif, studi kooperatif atau operasional. Bisa disimpulkan bahwa metode deskriptif ini ialah metode yang menuturkan dan menafsirkan data yang ada, misalnya tentang situasi yang dialami, satu hubungan, kegiatan, pandangan, sikap yang menampak, atau tentang satu proses yang sedang berlangsung, pengaruh yang sedang bekerja, kelainan yang sedang muncul, kecenderungan yang menampak, pertentangan yang meruncing, dan sebagainya.

Analisis deskriptif yang dilakukan yaitu, persiapan lokasi pengukurann, pengambilan data historis dan pengamatan fisik, penentuan panjang kabel serta lokasi joint, pengujian pd measurement dan mapping dengan pendekatan damped ac (dac), pemetaan jalur kabel. Data deskriptif berupa data angka, agar dapat memberikan gambaran secara teratur, ringkas dan jelas, mengenai suatu gejala, peristiwa atau keadaan, sehingga dapat ditarik pengertian atau makna tertentu. Dan juga berupa table-tabel, serta grafik risiko kondisi kabel pada saat Partial Discharge.

\section{HASIL DAN PEMBAHASAN}

Penelitian ini dilakukan pada penyulang Kambing di segmen TD 09 ke PM 4A dan segmen tersebut dalam keadaan offline atau bebas tegangan. Penelitian dilakukan dengan melihat nilai pelepasan muatan terendah, nilai pelepasan muatan tertinggi, dan nilai tegangan.

Penelitian ini dilakukan pengukuran pelepasan muatan dan tegangan pada setiap fasa pada segmen tersebut. Setelah dilakukan pengukuran pelepasan muatan satu segmen maka selanjutnya dilakukan analisis data untuk mengetahui nilai Partial Discharge kemudian nilai tersebut diakumulasikan hingga menjadi kesimpulan kondisi resiko kegagalan kabel. Setelah mengetahui kondisi resiko kegagalan kabel dapat diketahui hasil rekomendasi segmen. Sehingga dengan adanya hasil rekomendasi segmen dapat segera ditindak lanjuti sesuai dengan hasil rekomendasi segmen. Yang mana akan menjaga kontinuitas penyaluran distribusi tenaga listrik ke konsumen.

Data berikut ini menjelaskan pengenal segmen yang meliputi nama penyulang, nama segmen, panjang segmen, jumlah jointing dapat dilihat pada Tabel 1 berikut.

\begin{tabular}{crrr}
\hline Penyulang & \multicolumn{2}{c}{ Kambing } & Tahun \\
\hline \multirow{2}{*}{ Segmen } & TD 09 & $\begin{array}{c}\text { PM } \\
\text { 4A }\end{array}$ & 2001 \\
\hline
\end{tabular}

\begin{tabular}{cccc}
\hline Location (M) & \multicolumn{2}{c}{$\begin{array}{c}\text { Jointing } \\
\text { Nomor }\end{array}$} & Keterangan \\
\hline Termination & $0 \mathrm{~m}$ & & $\begin{array}{c}\text { Awal } \\
\text { Panjang Kabel } \\
67 \mathrm{~m}\end{array}$ \\
Cablepart & $67 \mathrm{~m}$ & & $\begin{array}{c}\text { Lokasi jointing } \\
\text { di } 67 \mathrm{~m}\end{array}$ \\
Joint & $67 \mathrm{~m}$ & 1 & $\begin{array}{c}\text { Panjang Kabel } \\
63 \mathrm{~m}\end{array}$ \\
Cablepart & $63 \mathrm{~m}$ & & $\begin{array}{c}\text { Lokasi jointing } \\
\text { di } 130 \mathrm{~m}\end{array}$ \\
Joint & $130 \mathrm{~m}$ & 2 & $\begin{array}{c}\text { Panjang Kabel } \\
59 \mathrm{~m}\end{array}$ \\
Cablepart & $59 \mathrm{~m}$ & &
\end{tabular}




\begin{tabular}{|c|c|c|c|}
\hline Joint & $189 \mathrm{~m}$ & 3 & $\begin{array}{c}\text { Lokasi jointing } \\
\text { di } 189 \mathrm{~m}\end{array}$ \\
\hline Cablepart & $120 \mathrm{~m}$ & & $\begin{array}{c}\text { Panjang Kabel } \\
120 \mathrm{~m}\end{array}$ \\
\hline Joint & $309 \mathrm{~m}$ & 4 & $\begin{array}{c}\text { Lokasi jointing } \\
\text { di } 309 \mathrm{~m}\end{array}$ \\
\hline Cablepart & $168 \mathrm{~m}$ & & $\begin{array}{c}\text { Panjang Kabel } \\
168 \mathrm{~m}\end{array}$ \\
\hline Joint & $477 \mathrm{~m}$ & 5 & $\begin{array}{l}\text { Lokasi jointing } \\
\text { di } 477 \mathrm{~m}\end{array}$ \\
\hline Cablepart & $195 \mathrm{~m}$ & & $\begin{array}{c}\text { Panjang Kabel } \\
195 \mathrm{~m}\end{array}$ \\
\hline Joint & $672 \mathrm{~m}$ & 6 & $\begin{array}{c}\text { Lokasi jointing } \\
\text { di } 672 \mathrm{~m}\end{array}$ \\
\hline Cablepart & $77 \mathrm{~m}$ & & $\begin{array}{c}\text { Panjang Kabel } \\
77 \mathrm{~m}\end{array}$ \\
\hline $\begin{array}{l}\text { Termination } \\
\text { Jumlah }\end{array}$ & $749 \mathrm{~m}$ & & Akhir \\
\hline $\begin{array}{c}\text { Titik } \\
\text { Jointing }\end{array}$ & 6 & & \\
\hline
\end{tabular}

Tabel 1. Data Input Pengenal Segmen

Berikut Gambar 1 yang merupakan grafik hasil kalibrasi pada segmen ini.

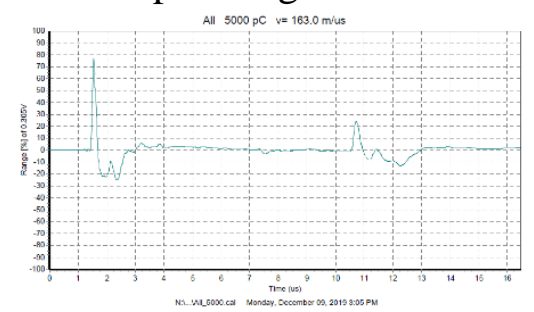

Gambar 1. Grafik Hasil Kalibrasi

Berdasarkan Gambar 1. tersebut hasil kalibrasi pada skala adalah $5000 \mathrm{pC}$, dengan nilai velocitynya adalah $163.0 \mathrm{~m} / \mathrm{us}$. Nilai velocity tersebut dikarenakan pada saat input jenis kabel, kabel yang digunakan adalah jenis XLPE, sehingga velocity yang muncul di range $158.0 \mathrm{~m} / \mathrm{us}$ - $166.0 \mathrm{~m} / \mathrm{us}$.

Pada Gambar 1. tersebut terdapat bentuk gelombang dengan puncak dan lembah. Pada IEEE 400.3-2006, kalibrasi tidak boleh melebihi presentase $80 \%$. Dan kalibrasi yang didapat $t_{1}$ harus lebih tinggi daripada $t_{2}$. Dan $t_{2}$ tidak boleh melebihi dari $t_{1}$. Pada Gambar 1 dapat dicari tahu panjang segmen dengan rumus dan penyelesaian diatas dapat diketahui panjang segmen tersebut adalah $749 \mathrm{~m}$.

Pengukuran dilakukan pada segmen TD 09 ke PM 4A. pengukuran dilakukan pada saat segmen bebas tegangan atau pada saat tidak beroperasi. Karena sesuai dengan Standard Operasional Prosedure, pengukuran diharuskan dalam keadaan bebas tegangan atau pada saat tidak beroperasi Pengukuran dilakukan dengan mengikuti langkah penelitian dengan melihat Tabel 1 sebagai data input pengenal segmen. Dan Tabel 2. data hasil pengukuran.

Tabel 2 adalah tabel hasil pengukuran dimulai dari L1 sampai dengan L3. Dengan pengujian dari tegangan terkecil $0,5 \mathrm{U}_{0}$ sampai dengan 2,0 $\mathrm{U}_{0}$. Pengukuran 2,0 $\mathrm{U}_{0}$ tidak dilakukan karena tidak direkomendasikan oleh PLN untuk melakukan pengukuran tersebut. Terdapat nilai Capasitance dari kabel tersebut masing-masing fasa yang hampir sama yaitu sebesar $412.37 \mu F$. Nilai Frequency pada L1 yaitu sebesar $412.37 \mathrm{~Hz}$. Lalu pada L2 sebesar $410.27 \mathrm{~Hz}$, dan pada L3 yaitu sebesar $412.37 \mathrm{~Hz}$. Diel losses adalah ketika pengujian total sampai dengan pengujian $1,7 \mathrm{U}_{0}$ terjadi kebocoran 1,2 $\%$ pada tiap fasa L1, L2, dan L3. Pada Tabel 4.2. terdapat nilai GroundNoise yaitu pada L1 sebesar 96 pC, L2 sebesar 99 pC, dan L3 sebesar $92 \mathrm{pC}$.

Dibawah ini merupakan Tabel 2 data hasil pengukuran

Tabel 2. Data Hasil Pengukuran

\begin{tabular}{|c|c|c|c|}
\hline & L1 & $\mathrm{L} 2$ & L3 \\
\hline $\begin{array}{c}\text { GroundNoise } \\
{[\mathrm{pC}]}\end{array}$ & $96 \mathrm{pC}$ & $99 \mathrm{pC}$ & $92 \mathrm{pC}$ \\
\hline $\begin{array}{l}\text { PDIV [kV } \\
\text { RMS] }\end{array}$ & $17.3 \mathrm{kV}$ & $17.3 \mathrm{kV}$ & $17.3 \mathrm{kV}$ \\
\hline $\begin{array}{c}\text { PDEV [kV } \\
\text { RMS] }\end{array}$ & $8 \mathrm{kV}$ & $8 \mathrm{kV}$ & $8 \mathrm{kV}$ \\
\hline $\begin{array}{c}\text { PDmax [pC] } \\
\text { (PDIV) }\end{array}$ & $\begin{array}{c}18166 \\
\mathrm{pC}\end{array}$ & $\begin{array}{c}55293 \\
\text { pC }\end{array}$ & $\begin{array}{c}45610 \\
\mathrm{pC}\end{array}$ \\
\hline $\begin{array}{l}\text { PDlevel [pC] } \\
\text { (PDIV) }\end{array}$ & $\begin{array}{c}12891 \\
\mathrm{pC}\end{array}$ & $\begin{array}{c}38640 \\
\text { pC }\end{array}$ & $\begin{array}{c}29040 \\
\text { pC }\end{array}$ \\
\hline $\begin{array}{c}\text { PDmax }[\mathrm{pC}] \\
\text { (Uo) }\end{array}$ & $535 \mathrm{pC}$ & $525 \mathrm{pC}$ & $524 \mathrm{pC}$ \\
\hline $\begin{array}{l}\text { PDlevel [pC] } \\
\text { (Uo) }\end{array}$ & $424 \mathrm{pC}$ & $281 \mathrm{pC}$ & $397 \mathrm{pC}$ \\
\hline $\begin{array}{c}\text { PDmax [pC] } \\
(1.7 * \text { Uo })\end{array}$ & $\begin{array}{c}41031 \\
\mathrm{pC}\end{array}$ & $\begin{array}{c}54058 \\
\mathrm{pC}\end{array}$ & $\begin{array}{c}44733 \\
\mathrm{pC}\end{array}$ \\
\hline $\begin{array}{l}\text { PDlevel [pC] } \\
\quad(1.7 * \text { Uo })\end{array}$ & $\begin{array}{c}19418 \\
\mathrm{pC}\end{array}$ & $\begin{array}{c}14508 \\
\mathrm{pC}\end{array}$ & $\begin{array}{c}17339 \\
\mathrm{pC}\end{array}$ \\
\hline $\begin{array}{c}\text { PDmax }[\mathrm{pC}] \\
\left(2.0^{*} \mathrm{Uo}\right)\end{array}$ & $\begin{array}{l}\text { Tidak } \\
\text { diukur }\end{array}$ & $\begin{array}{l}\text { Tidak } \\
\text { diukur }\end{array}$ & $\begin{array}{l}\text { Tidak } \\
\text { diukur }\end{array}$ \\
\hline $\begin{array}{l}\text { PDlevel [pC] } \\
\quad\left(2.0^{*} \text { Uo }\right)\end{array}$ & $\begin{array}{l}\text { Tidak } \\
\text { diukur }\end{array}$ & $\begin{array}{l}\text { Tidak } \\
\text { diukur }\end{array}$ & $\begin{array}{c}\text { Tidak } \\
\text { diukur }\end{array}$ \\
\hline $\begin{array}{c}\text { Capasitance } \\
{[\mathrm{uF}]}\end{array}$ & $0.2 \mathrm{uF}$ & $\begin{array}{c}0.202 \\
\mathrm{uF}\end{array}$ & $0.2 \mathrm{uF}$ \\
\hline Frequency [Hz] & $\begin{array}{c}412.37 \\
\mathrm{~Hz}\end{array}$ & $\begin{array}{c}410.27 \\
\mathrm{~Hz}\end{array}$ & $\begin{array}{c}412.37 \\
\mathrm{~Hz}\end{array}$ \\
\hline Diel. Losses \% & $1.20 \%$ & $1.20 \%$ & $1.20 \%$ \\
\hline
\end{tabular}


Berikut adalah Gambar 2 merupakan grafik GroundNoise pada L1.

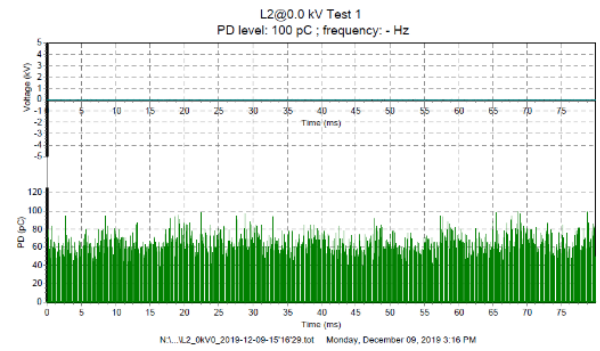

Gambar 2. GroundNoise Pada Fasa L1

Berdasarkan Gambar 2. terlihat bahwa hasil pengukuran GroundNoise pada fasa L1 yaitu 96 pC. Berdasarkan Gambar 4.2 terlihat bahwa hasil pengukuran GroundNoise pada Fasa L1 yaitu 94 pC. Dan pada saat tegangan 0 V. Menunjukan nilai pC yang kecil karena tidak adanya tegangan kerja, yaitu tegangan yang digunakan untuk pengukuran. Atau dapat dikatakan saat tegangan $0 \mathrm{~V}$. Kemudian berikut adalah gambar grafik GroundNoise pada L2.

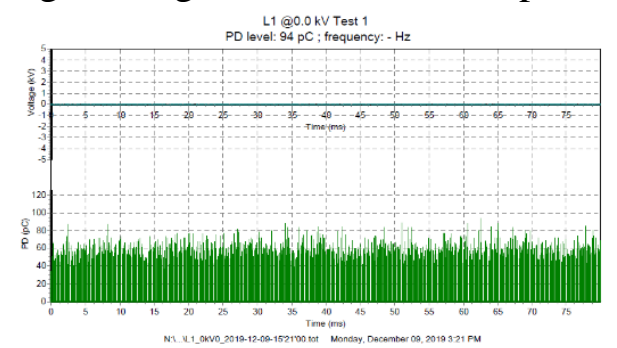

Gambar 3. GroundNoise Pada Fasa L2

Berdasarkan Gambar 3. terlihat bahwa hasil pengukuran GroundNoise pada fasa L2 yaitu 99 pC. Berdasarkan Gambar 3 terlihat bahwa hasil pengukuran GroundNoise pada Fasa L1 yaitu 100 pC. Dan pada saat tegangan 0 V. Menunjukan nilai $\mathrm{pC}$ yang kecil karena tidak adanya tegangan kerja, yaitu tegangan yang digunakan untuk pengukuran. Atau bisa dikatakan saat tegangan $0 \mathrm{~V}$. Kemudian berikut adalah Gambar 4. grafik GroundNoise pada L3.

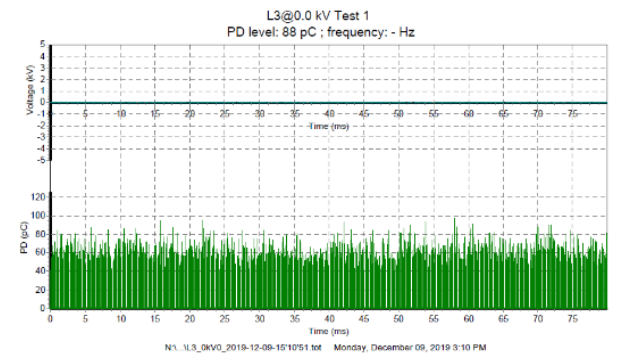

Gambar 4. GroundNoise Pada Fasa L3

Berdasarkan Gambar 4. terlihat bahwa hasil pengukuran GroundNoise pada fasa L3 yaitu 92 pC. Berdasarkan Gambar 4.4 terlihat bahwa hasil pengukuran GroundNoise pada Fasa L3 yaitu 88 pC. Dan pada saat tegangan 0 V. Menunjukan nilai $\mathrm{pC}$ yang kecil karena tidak adanya tegangan kerja, yaitu tegangan yang digunakan untuk pengukuran. Atau bisa dikatakan saat tegangan $0 \mathrm{~V}$

Data berikut ini adalah nilai tegangan saat muncul Partial Discharge yaitu meliputi PDIV dan PDEV dapat dilihat pada Tabel 3.

Tabel 3. Tegangan Saat Muncul Partial Discharge

\begin{tabular}{cccc}
\hline & L1 & L2 & L3 \\
\hline PDIV [kV & 17.3 & 17.3 & 17.3 \\
RMS] & $\mathrm{kV}$ & $\mathrm{kV}$ & $\mathrm{kV}$ \\
PDEV [kV & 8 & 8 & 8 \\
RMS] & & &
\end{tabular}

Berdasarkan Tabel 3. menunjukan bahwa nilai tegangan naik (PDIV) saat Partial Discharge awal muncul sebesar $17,3 \mathrm{kV}$, nilai tegangan (PDIV) tersebut sama besarnya pada tiap Fasa L1, L2, dan L3. Pada saat tegangan menurun, Partial Discharge

menghilang yaitu di $8 \mathrm{kV}$, nilai tegangan (PDEV) tersebut sama besarnya pada tiap Fasa L1, L2, L3.

Pengukuran Partial Discharge saat PDIV. Dengan tegangan kerja 1,5 $\mathrm{U}_{0}$. Berdasarkan nilai tegangan pada Tabel 3. akan muncul nilai Partial Discharge dapat dilihat pada Tabel 4. berikut

Tabel 4. Pengukuran Partial Discharge saat PDIV

\begin{tabular}{llll}
\hline & L1 & L2 & L3 \\
\hline PDmax [pC] & 41031 & 54058 & 44733 \\
$(1.7 *$ Uo $)$ & pC & pC & pC \\
PDlevel [pC] & 19418 & 14508 & 17339 \\
$(1.7 *$ Uo $)$ & pC & pC & pC \\
\hline
\end{tabular}

Berdasarkan Tabel 4. nilai Partial Discharge saat PDIV. Terdapat PD max merupakan nilai Partial Discharge tertinggi yang muncul. Dan dapat dikatakan juga PD max itu seberapa besar potensi Partial Discharge yang muncul. PD level merupakan nilai Partial Discharge yang muncul.

Menunjukan nilai L1 PD max dengan PD level dengan nilai $18.166 \mathrm{pC}$ dan $12.891 \mathrm{pC}$. Pada L2 dan L3 nilai PD max berturut-turut berkisar 55.293 pC dan 45.610 pC. Dan nilai PD levelnya berkisar 38.640 pCdan 29.040 pC. Terdapat perbedaan PD max dengan PD level pada tiap fasa L1, L2, dan L3. Dikarenakan PD 
max merupakan nilai partial discharge yang muncul dengan nilai tertinggi. Dan PD level merupakan nilai partial discharge yang muncul.

Pengukuran Partial Discharge saat tegangan kerja $1 \mathrm{U}_{0}$. Berdasarkan nilai tegangan tegangan kerja $1 \mathrm{U}_{0}$ atau setara dengan $11,5 \mathrm{kV}$ pada Tabel 4.3. akan muncul nilai Partial Dishcarge dapat dilihat pada Tabel 5.

Tabel 5. Pengukuran Partial Discharge saat 1 Uo

\begin{tabular}{llll}
\hline & L1 & L2 & L3 \\
\hline $\begin{array}{l}\text { PDmax } \\
\text { [pC] (Uo) }\end{array}$ & $535 \mathrm{pC}$ & $525 \mathrm{pC}$ & $524 \mathrm{pC}$ \\
$\begin{array}{l}\text { PDlevel } \\
\text { [pC] (Uo) }\end{array}$ & $424 \mathrm{pC}$ & $281 \mathrm{pC}$ & $397 \mathrm{pC}$
\end{tabular}

Berdasarkan Tabel 5. nilai Partial Discharge saat $1 \mathrm{U}_{0}$ menunjukan nilai L1 PD max dengan PD level yang tidak berbeda jauh. Nilai PD Max pada L1 dan L2 sebesar 535 pC dan 424 pC. Pada L2 dan L3 nilai PD max berturut-turut berkisar $525 \mathrm{pC}$ pC dan $281 \mathrm{pC}$. Dan nilai PD levelnya berkisar 524 pC dan 397 $\mathrm{pC}$.

Pengukuran Partial Discharge dengan tegangan kerja 1,7 $\mathrm{U}_{0}$. Berdasarkan Tabel 3. nilai tegangan tegangan kerja $1,7 \mathrm{U}_{0}$ atau setara dengan 19,55 kV akan muncul nilai Partial Discharge dapat dilihat pada Tabel 6.

Tabel 6. Pengukuran Partial Discharge saat 1,7 Uo

\begin{tabular}{llll}
\hline & L1 & L2 & L3 \\
\hline PDmax [pC] & 41031 & 54058 & 44733 \\
$(1.7 *$ Uo $)$ & $\mathrm{pC}$ & $\mathrm{pC}$ & $\mathrm{pC}$ \\
PDlevel [pC] & 19418 & 14508 & 17339 \\
$(1.7 *$ Uo $)$ & $\mathrm{pC}$ & $\mathrm{pC}$ & $\mathrm{pC}$ \\
\hline
\end{tabular}

Berdasarkan Tabel 6. nilai Partial Discharge saat tegangan kerja $1,7 \quad \mathrm{U}_{0}$ menunjukan nilai L1 PD max sebesar 41.031 pC dan PD level sebesar 19.418 pC. Pada L2 dan L3 nilai PD max berturut-turut berkisar 54.058 pC dan 44.733 pC. Dan nilai PD levelnya berkisar 14.508 pC dan 17.339 pC. Berikut adalah hasil PD mapping dari analisa manual dari segmen tersebut, dapat dilihat pada gambar 5 dan gambar 6

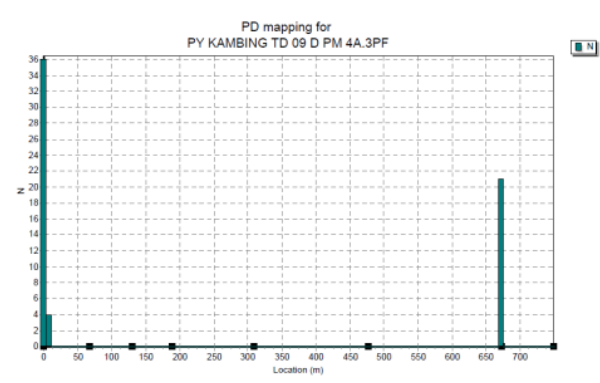

Gambar 5. Pemetaan Nilai Partial Discharge Penyulang Kambing Segmen TD 09 PM 4A

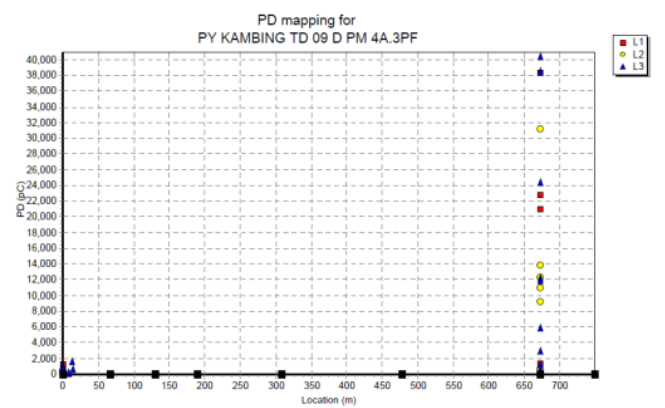

Gambar 6. Pemetaan Nilai Partial Discharge Penyulang Kambing Segmen TD 09 PM 4A

Status kabel terhadap tegangan muncul Partial Discharge, dapat dilihat dari Tabel 3. Tegangan Saat Muncul Partial Discharge. Nilai PDIV pada tiap fasa L1, L2, dan L3 sebesar 17,3 $\mathrm{kV}$. Dan nilai PDEV pada tiap fasa L1, L2 dan L3 sebesar 8,0 kV. Mengacu pada Tabel 2.2. Status Kabel Terhadap Tegangan Muncul PD. Nilai PDIV sebesar $17,3 \mathrm{kV}$ berada diatas tegangan nominal $1 \mathrm{U}_{0}$ atau $11,5 \mathrm{kV}$, dapat diartikan PDIV > Uo. Nilai PDEV sebesar $8 \mathrm{kV}$ berada dibawah tegangan nominal $1 \mathrm{U}_{0}$ atau 11,5 $\mathrm{kV}$, dapat diartikan PDEV $<\mathrm{U}_{0}$. Sehingga PDIV $>\mathrm{U}_{0}$ dan PDEV < $\mathrm{U}_{0}$ masuk kategori status kabel cukup buruk dengan Point 2.

Status kabel terhadap besar Partial Discharge. Pengukuran Partial Discharge saat 1 $\mathrm{U}_{0}$. Nilai PD max pada L1 sebesar 535 pC, L2 sebesar 525 pC, dan pada L3 sebesar 524 pC. Nilai PD level pada L1 sebesar 424 pC, L2 sebesar 281 pC, dan pada L3 sebesar 397 pC. Mengacu pada Tabel 2.3. Status Kabel Terhadap Besar Pelepasan Muatan. Nilai PD max berkisar diantara 525 pC sampai dengan 535 pC. Dan nilai PD level berkisar 281 pC sampai dengan 424 pC. Dapat disimpulkan nilai Partial Discharge berkisar 500 pC. Sehingga dapat diartikan besar muatan dibawah atau sama dengan 500 pC, $\mathrm{Y}<500 \mathrm{pC}$ atau $\mathrm{Y}=500 \mathrm{pC}$ masuk kategori status kabel baik dengan point 1 .

Status Kondisi dan Resiko Kabel Terhadap Pelepasan Muatan dan Tegangan. 
Status kabel terhadap tegangan muncul Partial Discharge yaitu PDIV > $\mathrm{U}_{0}$ masuk kategori status kabel cukup buruk dengan Point 2. Dan status kabel terhadap Partial Discharge besar muatan dibawah atau sama dengan $500 \mathrm{pC}, \mathrm{Y}<$ $500 \mathrm{pC}$ atau $\mathrm{Y}=500 \mathrm{pC}$ masuk kategori status kabel baik dengan point 1 . Jika pont 2 dan point 1 dijumlahkan maka hasil jumlahnya poin 3. Poin 3 dapat disimpulkan pada Tabel 2.4. dan juga Gambar 2.20. dengan warna hijau tua. Resiko kegagalan kabel pada segmen TD 09 to PM 4A adalah rendah dan status kabel tersebut cukup baik.

Hasilnya yaitu pada segmen tersebut kondisi resiko kegagalan kabel pada level rendah dan status kabel tersebut cukup baik yang di simbolkan dengan warna hijau tua. Tindak lanjutnya yaitu dalam jangka waktu 12 bulan, segmen ini harus kembali diukur untuk mengetahui kondisi resiko kegagalan kabel.

\section{KESIMPULAN DAN SARAN}

\section{Kesimpulan}

Berdasarkan pembahasan yang telah diuraikan sebelumnya, maka diperoleh kesimpulan. Berdasarkan hasil penelitian yang sudah dilakukan oleh peneliti menyatakan bahwa kondisi resiko kegagalan kabel terhadap pelepasan muatan (partial discharge) pada Penyulang Kambing Segmen TD 09 to PM 4A adalah rendah dan cukup baik. Berdasarkan hasil analisis status kabel terhadap tegangan muncul partial discharge nilai PDIV sebesar $17,3 \mathrm{kV}$ berada diatas tegangan nominal $1 \mathrm{U}_{0}$, atau setara 11,5 kV dapat diartikan PDIV > Uo. Nilai PDEV sebesar $8 \mathrm{kV}$ berada dibawah tegangan nominal $1 \mathrm{U}_{0}$ atau $11,5 \mathrm{kV}$, dapat diartikan PDEV $<\mathrm{U}_{0}$. Sehingga PDIV $>\mathrm{U}_{0}$ dan PDEV $<\mathrm{U}_{0}$ masuk kategori status kabel cukup buruk dengan Point 2. Status kabel terhadap besar pelepasan muatan. Nilai PD max berkisar diantara 525 pC sampai dengan 535 pC. Dan nilai PD level berkisar 281 pC sampai dengan 424 pC. Dapat disimpulkan nilai Partial Discharge berkisar 500 pC. Sehingga dapat diartikan besar muatan dibawah atau sama dengan $500 \mathrm{pC}, \mathrm{Y}<500 \mathrm{pC}$ atau $\mathrm{Y}=$ 500 pC masuk kategori status kabel baik dengan point 1 .

Status kabel terhadap tegangan muncul Partial Discharge PDIV $>\mathrm{U}_{0}$ dan PDEV $<\mathrm{U}_{0}$ masuk kategori status kabel cukup buruk dengan Point 2. Dan status kabel terhadap Partial Discharge besar muatan dibawah atau sama dengan $500 \mathrm{pC}, \mathrm{Y}<500 \mathrm{pC}$ atau $\mathrm{Y}=500 \mathrm{pC}$ masuk kategori status kabel baik dengan point 1 . Jika pont 2 dan point 1 dijumlahkan maka hasilnya poin 3 . Poin 3 dapat disimpulkan dengan warna hijau tua. Resiko kegagalan kabel pada segmen TD 09 to PM 4A adalah rendah dan status kabel tersebut cukup baik. Tindak lanjutnya yaitu dalam jangka waktu 12 bulan, segmen ini harus kembali diukur untuk mengetahui kondisi resiko kegagalan kabel.

\section{Saran}

Pada penelitian analisis Partial
Discharge pada saluran kabel tegangan menengah $20 \mathrm{kV}$ yang dilakukan pada Penyulang Kambing Segmen TD 09 to PM 4A, selama penelitian berlangsung ditemukan bahwa status kondisi resiko kegagalan kabel rendah atau cukup baik. Sehingga perlu tetap dipantau atau diamati agar tidak terjadi Partial Discharge yang dapat menyebabkan terjadi kegagalan kabel yang merembet ke pasokan distribusi tenaga listrik ke konsumen. Jika dalam kondisi status kabel cukup baik, maka perlu dicek dan dilakukan pengukuran kembali dalam jangka waktu 1 tahun kemudian. Agar dapat diketahui kondisi status kabel yang terbaru.

Penelitian ini memiliki keterbatasan keterkaitan dengan segmen, karena keterbatasan waktu peneliti. Penelitian selanjutnya disarankan untuk melakukan penelitian pada segmen yang lebih panjang, tahun pemasangan kabel, dan jumlah beban yang tinggi. Hal tersebut menarik untuk diteliti karena setiap Panjang segmen, tahun pemasangan kabel, dan jumlah beban yang tinggi dapat mempengaruhi kualitas kabel tegangan menengah pada jaringan distribusi tenaga listrik.

\section{DAFTAR PUSTAKA}

[1] Yantekbansel. (2012). Keuntungan dan Kerugian Penggunaan SUTM dan SKTM, https://yantekbansel.wordpress.com/2012 /07/02/keuntungan-dan-kerugianpenggunaan-sutm-dan-sktm/ diakses pada 28 Juli 2019 pada pukul 20.30 WIB

[2] Michael Agustinus (2017). Listrik Kemang Hingga Ragunan Sempat Mati 3 Jam, PLN Minta Maaf, https://finance.detik.com/energi/d3639984/listrik-kemang-hingga-ragunansempat-mati-3-jam-pln-minta-maaf. Diakses pada 28 Juli 2019 
[3] Salim Agus, Rizal Sultan Ahmad. (2016) Analisis Perbandingan Sistem Saluran Kabel Udara Tegangan Menengah (SKUTM) Dan Saluran Kabel Tanah Tegangan Menengah (SKTM).

[4] Renville Sapulette (1996). Pengaruh Internal Partial Discharge Kabel Terhadap Kegagalan Isolasi. Tesis Program Magister Universitas Indonesia

[5] Supriadi, L. Firman, J. (2016). Studi Analisis Pengaruh Partial Discharge Pada SKTM Terhadap Kehandalan Penyulang, Jurnal Energi \& Kelistrikan 8(2):67-73

[6] Jurjani Firman. (2015). Analisis Dan Resiko Partial Discharge Pada Kabel Tegangan Menengah. Jakarta : Jurusan Teknik Elektro Sekolah Tinggi Teknik PLN

[7] Maxmanrone (2019). Pengertian Analisis, https://www.maxmanroe.com/vid/umum/ pengertian-analisis.html. Diakses pada 29 Juli 2019 pukul 22.00 WIB

[8] Standar Perusahaan Listrik Negara 43-54:1995

[9] William Thue (1990). Electrical Power Cable Engineering. CRC Press : London

[10] Institute of Electrical and Electronics Engineer 400.4-2013, Guide for Field Testing of Shielded Power Cable Systems Rated $5 \mathrm{kV}$ and Above with Damped Alternating Current (DAC) Voltage, IEEE

[11] Institute of Electrical and Electronics Engineers 400.3-2006, Guide for Partial Discharge Testing of Shielded Power Cable Systems in a Field Environment, IEEE.

[12] PUSLITBANG. (2010). Studi Asesmen Kondisi Kabel 20 kV. Laporan Penelitian Pusat Pengembangan Ketenagalistrikan

[13] Hermawan Pungkie Oktharia. (2012). Analisis Partial Discharge Pada Pengujian Kabel XLPE Tegangan Menengah Satu Inti dan Tiga Inti. Jakarta:Universitas Indonesia 